\title{
Espécies de Parmotrema (Parmeliaceae, Ascomycota) do litoral centro-sul do estado de São Paulo, Brasil. I. Grupos químicos girofórico e lecanórico
}

\author{
Michel Navarro Benatti ${ }^{1,2}$ e Marcelo Pinto Marcelli ${ }^{1}$
}

Recebido em 15/05/2008. Aceito em 30/01/2009

\begin{abstract}
RESUMO - (Espécies de Parmotrema (Parmeliaceae, Ascomycota) do litoral centro-sul do estado de São Paulo, Brasil. I. Grupos químicos girofórico e lecanórico). O levantamento das espécies pertencentes aos gêneros de grandes parmélias do litoral centro-sul do Estado de São Paulo revelou a ocorrência de sete espécies de Parmotrema (talos foliosos de lobos arredondados em geral com mais de $0,5 \mathrm{~cm}$ larg. com margens inferiores não rizinadas) contendo como constituintes químicos medulares os ácidos girofórico e lecanórico, tipicamente reconhecidos pela cor avermelhada que resulta dos testes de coloração com hipoclorito de cálcio. São apresentados uma chave de identificação, descrições, comentários e ilustrações baseados em material brasileiro.

Palavras-chave: costões rochosos, liquens, manguezal, restinga.
\end{abstract}

ABSTRACT - (Species of Parmotrema (Parmeliaceae, Ascomycota) of the central-southern coast of São Paulo state, Brazil. I. Gyrophoric and lecanoric chemical groups). In a survey of the species pertaining to genera of large parmeliae occurring in the coastal areas of central-southern São Paulo state, Brazil, seven species of Parmotrema (foliose thalli with rounded lobes usually more than $0.5 \mathrm{~cm}$ wide with nude lower margins) containing gyrophoric and lecanoric acids as main medullar substances were found. These are typically recognized by the red staining calcium hypochlorite spot tests. Identification key, descriptions, comments, and illustrations based on Brazilian material are provided for these species.

Key words: rocky shores, lichens, mangrove, restinga

\section{Introdução}

O gênero Parmotrema A. Massal. é caracterizado pelos lobos de ápices largos e arredondados (com mais de $0,5 \mathrm{~cm}$, muitas vezes ultrapassando 2 ou $3 \mathrm{~cm}$ de largura), ausência de pseudocifelas (poros com extravasamento de hifas medulares), ocorrência freqüente de cílios marginais, ampla zona marginal do córtex inferior nua, rizinas geralmente simples, e ascósporos elipsóides de paredes espessas (Brodo et al. 2001; Nash \& Elix 2002). Mais de trezentas espécies são conhecidas em todo o mundo (Nash \& Elix 2002), das quais mais de 90 são citadas para o Brasil (Marcelli 2004).

Todas as espécies apresentadas neste trabalho possuem como característica em comum a presença dos ácidos lecanórico ou girofórico medulares, reconhecidos em testes de coloração pelas reações $\mathrm{C}+\mathrm{e} \mathrm{KC}+$ róseo-avermelhadas, e por cromatografia em camada delgada (CCD) pelos típicos rastros UV+ esverdeados após o charring.

Esta pesquisa abrange todos os municípios da Baixada Santista localizados no litoral centro-sul do Estado de São Paulo situados abaixo do trópico de Capricórnio e compreendidos entre os municípios de Bertioga $\left(46^{\circ} 08^{\prime} 03^{\prime} \mathrm{W}\right.$, $23^{\circ} 51^{\prime} 17^{\prime \prime}$ S) e Cananéia $\left(47^{\circ} 55^{\prime} 33^{\prime \prime} \mathrm{W}, 25^{\circ} 00^{\prime} 53^{\prime \prime} \mathrm{S}\right)$.

O clima da região é influenciado por frentes frias formadas ao longo do litoral sul do país, que são acompanhadas de ventos de componente $\mathrm{S}$ (sul), carregados de umidade, prevalecendo sobre os de E (leste) (Santos 1965). A atmosfera apresenta média da umidade relativa do ar elevada ao longo do ano, entre 70 e $90 \%$, devido à posição geográfica e meteorológica da região (CETESB 1985). A maior quantidade de precipitação pluviométrica ocorre de outubro a março, representando $70 \%$ da média anual, sendo que a média das precipitações fica freqüentemente na faixa dos 2000 a $2500 \mathrm{~mm}$ (Santos 1965; Lamberti 1969), podendo variar de 2000 a $3000 \mathrm{~mm}$ de uma área para outra do litoral. O regime térmico apresenta fevereiro como o mês mais quente e julho como o mês mais frio do ano, tendo sido registradas médias anuais ao redor de $22^{\circ} \mathrm{C}$, com máximas de até $40,2{ }^{\circ} \mathrm{C}$ e mínimas de até $3,2{ }^{\circ} \mathrm{C}$ em Itanhaém (Santos 1965; Lamberti 1969).

Este trabalho objetivou realizar o levantamento das espécies de Parmotrema sensu stricto com ácidos girofórico e lecanórico medulares que ocorrem nos diversos ambientes do litoral centro-sul paulista, até então inexistente. São fornecidos chave artificial de identificação, descrições comentadas, dados das localidades e de ambientes para as espécies encontradas.

\section{Material e métodos}

Os ambientes estudados incluem (1) os costões rochosos, quase sempre despidos de vegetação e expostos à forte insolação, à salinidade da maré e à ação altamente energética das ondas; (2) a vegetação de restinga, constituída pelas matas de jundu e as florestas de restinga, que compõem grande parte da vegetação da planície costeira atrás da faixa das dunas, instaladas sobre as extensas faixas arenosas na orla marítima; (3) os manguezais, formações caracterizadas pelas florestas que se erguem sobre um substrato plano, lodoso, localizadas nas bordas de estuários e foz de rios, freqüentemente inundado pelas marés (Andrade \& Lamberti 1965; Andrade 1967; Eiten 1970).

A metodologia de coleta e triagem empregada foi a mesma descrita em Benatti \& Marcelli (2007). O material foi identificado conforme a metodologia descrita em Fink (1905), Galloway (1985) e Hale (1979). Foram realizadas excursões pontuais de coleta a várias localidades urbanas e naturais de todos os municípios da região (Bertioga, Santos, São Vicente, Praia Grande, Itanhaém, Mongaguá, Peruíbe, Iguape, Ilha Comprida e Cananéia, além de algum material de Ubatuba). Todo o material foi depositado no Herbário Maria Eneyda P. Kauffmann Fidalgo (SP), do Instituto de Botânica, em São Paulo.

Para as análises morfológicas foram observadas características macroscópicas e microscópicas dos espécimes, mediante uso de estereomicroscópio e microscópio óptico. Foram analisadas características de estruturas somáti-

1 Instituto de Botânica, Seção de Micologia e Liquenologia, São Paulo, SP, Brasil

2 Autor para correspondência: michel_benatti@yahoo.com.br 
cas e de reprodução, tanto direta como indireta dos talos (Benatti 2005). As análises químicas (testes de coloração, irradiação por luz UV e CCD com solvente C) foram baseadas em Asahina \& Shibata (1954), Walker \& James (1980), White \& James (1985), Hüneck \& Yoshimura (1996), Bungartz (2001) e Orange et al. (2001), com pequenas mudanças ou adaptações.

Embora sejam discutidos os aspectos mais relevantes pertinentes a cada uma das espécies identificadas, mais comparações e detalhes podem ser em Benatti (2005).

\section{Resultados e discussão}

No litoral centro-sul do Estado de São Paulo foram encontradas quatro espécies de Parmotrema contendo ácido girofórico medular e outras três contendo ácido lecanórico. Embora cinco delas já sejam mencionadas para São Paulo, existe apenas um trabalho brasileiro contendo chaves e descrições para algumas espécies deste grupo (Eliasaro \& Donha 2003).

Cinco espécies apresentam propagação direta por formação de sorédios [P. austrosinense (Zahlb.) Hale, P. eitenii Marcelli \& Benatti, P. indicum Hale, P. permutatum (Stirton) Hale e P. sancti-angeli (Lynge) Hale], e duas por formação de isídios [P. flavescens (Kremp.) Hale e P. tinctorum (Nyl.) Hale. Nenhuma espécie que apresente reprodução indireta, somente por formação de apotécios, foi encontrada. Par- motrema flavescens é saxícola, enquanto todas as demais espécies são corticícolas.

À exceção de alguns poucos espécimes de P. tinctorum, não foram encontrados esporos ou mesmo apotécios em quase todo o material. Foram encontrados conídios somente em espécimes de $P$. indicum, $P$. permutatum e $P$. sancti-angeli.

Para quase todas as espécies descritas aqui, os testes de coloração do córtex superior são $\mathrm{K}+$ amarelo (atranorina) e os da medula são $\mathrm{K}-, \mathrm{C}+$ róseo-avermelhado, $\mathrm{KC}+$ avermelhado, $\mathrm{P}-$, UV- (ácidos girofórico ou lecanórico). A exceção é $P$. flavescens, cujo córtex superior reage $\mathrm{K}-, \mathrm{KC}+$ amarelo, (ácido úsnico com traços de atranorina) e a medula $\mathrm{K}+$ amarelo®vermelho, $\mathrm{C}-, \mathrm{KC}$ similar à $\mathrm{K}$ porém diluto, $\mathrm{P}+$ amarelo e UV- (ácidos salazínico e girofórico). Apesar do ácido salazínico dificultar a detecção do ácido girofórico por testes de coloração, este aparece claramente em CCD. Já em P. permutatum, os testes de coloração medulares C e KC tanto das porções branca como pigmentada (eumitrinas) da medula ocasionalmente evoluem de róseos para alaranjados. Embora hajam exceções, há uma tendência dos testes $\mathrm{C}$ e $\mathrm{KC}$ do ácido girofórico tenderem mais ao róseo, enquanto que os do lecanórico mais ao vermelho.

Chave artificial de identificação para as espécies de Parmotrema sensu stricto contendo ácidos girofórico ou lecanórico do litoral centro-sul do estado de São Paulo

1a. Talo isidiado .2

1b. Talo sorediado .3

2a. Talo saxícola, córtex superior verde amarelado com ácido úsnico $(\mathrm{K}-)$, margens parcialmente ciliadas, isídios marginais ou sobre dobras do talo, medula $\mathrm{K}+$ amarelo $\rightarrow$ vermelho, com ácidos girofórico e salazínico 3. P. flavescens

2b. Talo corticícola, córtex superior cinza esverdeado com atranorina ( $\mathrm{K}+$ amarelado), margens sem cílios, isídios somente laminais, medula $\mathrm{K}$-, somente com ácido lecanórico 7. P. tinctorum 3a. Margens totalmente eciliadas, medula com ácido lecanórico ...................................................................... 3b. Margens ciliadas, cílios esparsos a freqüentes, de curtos a longos, medula com ácido girofórico .......................5

4a. Sorédios granulares, originados a partir de inchaços pustulares efêmeros, tornando-se corticados e mantendo o aspecto pustular ou adquirindo um aspecto isidióide; sorais marginais a submarginais irregulares; talo subcoriáceo

4b. Sorédios farinhosos, originados diretamente a partir das margens e nunca se tornando corticados; sorais marginais lineares estreitos e geralmente contínuos; talo membranáceo a submembranáceo. 1. P. austrosinense 5a. Medula branca na porção superior e parcialmente pigmentada amarela, salmão e ocre na porção inferior . 5. P. permutatum

5b. Medula totalmente branca, sem pigmentações...

6a. Margens esparsamente ciliadas, cílios curtos raramente maiores que $1 \mathrm{~mm}$ comp., conídios filiformes ca. 8-14 x $1 \mu \mathrm{m}$. 4. $P$. indicum 6b. Margens bastante ciliadas, exceto onde se formam sorais, cílios longos freqüentemente 1-6 mm comp., conídios sublageniformes ca. 5-8 x $1 \mu \mathrm{m}$. 6. P. sancti-angeli

1. Parmotrema austrosinense (Zahlb.) Hale, Phytologia 28(4): 335. 1974.

Parmelia austrosinensis Zahlb, Symbolae Sinica 3: 192. 1930.

Fig. 1a-b
Talo lobado a sublobado, verde acinzentado a verde cinzento pardo quando em herbário, até $9,0 \mathrm{~cm}$ diam., submembranáceo a membranáceo, ramulícola ou corticícola. Lobos de ramificação irregular, (1,5-) 3,0-6,5 (-9,5) mm larg., de 
contíguos a sobrepostos lateralmente, raramente amontoados no centro, de adnatos a pouco elevados, pouco adpressos, os ápices subarredondados, planos a subcôncavos, às vezes revolutos quando sorediados, as margens lisas, subplanas nas partes distais a ascendentes conforme produzem sorédios, tornando-se progressivamente mais onduladas em direção ao centro. Superfície contínua, às vezes transversalmente quebrada nas partes velhas, lisa. Lacínulas ausentes. Máculas ausentes. Cílios ausentes. Sorais lineares contínuos ou às vezes interrompidos, marginais, estreitos, ou raramente capitados submarginais, com sorédios farinhosos. Pústulas e isídios ausentes. Medula branca, sem pigmentações. Lado de baixo negro, raramente marrom escuro em alguns pontos, lustroso, com áreas lisas ou pouco rugosas. Margem inferior marrom clara, branca a creme clara quando em lobos sorediados, lustrosa, 1,5-10,0 mm, atenuadas quando marrons a nítidas quando creme ou brancas, lisas, pouco venadas ou pouco rugosas, nuas. Rizinas concoloridas, simples, muito raramente furcadas, $0,20-1,10 \times 0,05-0,10 \mathrm{~mm}$, poucas, agrupadas, às vezes aglutinadas. Apotécios não encontrados. Picnídios bastante escassos, submarginais, de ostíolo negro. Conídios não encontrados.

Substâncias de importância taxonômica: atranorina (córtex superior) e ácido lecanórico (medula).

Material estudado: BRASIL. São Paulo: Praia Grande, Boqueirão, 7/I/1989, M.P.Marcelli et al. 4091 (SP); idem, 8/I/1989, próximo à Avenida General Mallet, M.P.Marcelli et al. 4120 (SP); idem, perto da Fortaleza de Itaipu, 27/ IX/1992, M.P.Marcelli \& O.Yano 14375, 14380 (SP). São Sebastião, Centro de Biologia Marinha da USP, 18/III/1988, M.P.Marcelli 2050, 2051, 2052, 2053, 2070, 2085, 2167, 2168, 2169, 2172, 2173, 2174 (SP); idem, morro entre a Praia do Segredo e a Praia do Cabelo Gordo de Dentro, 19/ III/1989, M.P.Marcelli 2314.

Distribuição: Oceania, Ásia, África, América do Norte, América Central, Caribe e América do Sul. Brasil: MG, PR, RS e SP (Hale 1965; Krog \& Swinscow 1981; Osorio et al. 1980; Fleig 1997; Ribeiro 1998; Eliasaro 2001).

Comentários: Esta espécie é caracterizada pelas margens sinuosas e eciliadas, continuamente delineadas com sorais estreitos compostos de sorédios farinhosos. Como a maioria dos lobos torna-se sorediado desde jovem, é comum uma coloração branca a creme típica nas margens inferiores de lobos sorediados predominando sobre a cor marrom dos lobos sem propágulos.

Nenhum dos espécimes estudados continha apotécios, e os picnídios são extremamente escassos. Ambos são sempre mencionados em trabalhos como sendo poucos ou ausentes. Fleig (1997) cita conídios filiformes, (9,0-) 10,0$16,0(-18,5) \mu \mathrm{m}$ comp., enquanto Elix (1994) mencionou conídios 10,0-14,0 $\mu \mathrm{m}$ compr. Quanto aos esporos, Hale (1965) mencionou 10,0-16,0 x 6,0-10,0 $\mu \mathrm{m}$, e Elix (1994) 12,0-20,0 x 7,0-10,0 $\mu \mathrm{m}$.

Parmotrema sancti-angeli (Lynge) Hale possui sorais marginais, no entanto mais espessados e de sorédios mais subgranulares que os de $P$. austrosinense. Os sorais são menos contínuos em $P$. sancti-angeli, que é bastante ciliada com cílios longos que variam de simples a furcados (com freqüência atingindo 5,0 mm comp. ou às vezes mais). Assim como também foi observado por Fleig (1997), P. sanctiangeli tem conídios sublageniformes e mais curtos $(6,5-7,0$ $\mu \mathrm{m})$ que os descritos para $P$. austrosinense.

Parmotrema eitenii difere pelo talo mais coriáceo de lobos mais largos, e pelos sorais marginais a submarginais, compostos de sorédios granulares de origem pustular, parcialmente corticados, aglutinando ou ascendendo. A coloração das margens inferiores de $P$. austrosinense apresenta diferenciação de cor em lobos sorediados (geralmente sendo clara), sendo que em $P$. eitenii estas são sempre marrons.

Parmotrema dilatatum (Vainio) Hale também tem margens sorediadas e eciliadas, mas difere de $P$. austrosinense pelos sorais lineares interrompidos nos ápices de lacínulas marginais, sorédios mais subgranulares, e tem como componentes químicos medulares os ácidos equinocárpico e protocetrárico ( $\mathrm{K}+$ amarelo, $\mathrm{C}-, \mathrm{KC}+$ róseo, $\mathrm{P}+$ alaranjado, $\mathrm{UV}-$ ).

Todos os espécimes estudados neste trabalho apresentam medidas de lobos um tanto quanto menores do que as citadas em literatura (Hale 1965; Fleig 1997; Ribeiro 1998; Eliasaro 2001). Entretanto, nenhuma outra diferença morfológica ou química foi encontrada.

\section{Parmotrema eitenii Marcelli \& Benatti, Bibliotheca} Lichenologica 96: 212. 2007.

Figura 2a-b

Talo lobado a sublobado, verde acinzentado a verdepardo quando em herbário, até 17,0 cm diam., subcoriáceo, corticícola. Lobos de ramificação irregular, 3,0-14,5 mm larg., sobrepostos lateralmente ou em parte pouco amontoados no centro, pouco adnatos a elevados, adpressos a pouco adpressos, às vezes tornando-se levemente pregueados e subcanaliculados, os ápices arredondados a subarredondados, côncavos a subcôncavos ou menos freqüentemente subplanos, as margens lisas a subcrenadas, subonduladas a onduladas, às vezes bastante sinuosas em lobos sorediados, subascendentes e involutas, inteiras. Superfície contínua, com poucas quebras mais restritas às partes velhas, de lisa a rugosa. Lacínulas ausentes, às vezes formam-se lóbulos jovens adventícios em partes velhas, simples, arredondados, subplanos a subcôncavos, 1,0-3,5 x 1,0-3,0 $\mu \mathrm{m}$, lado de baixo concolorido à margem inferior. Máculas ausentes a escassas, fracas, lineares, laminais, às vezes originadas por quebras. Cílios ausentes. Sorais lineares marginais interrompidos a irregulares ou em dobras estendendo-se sobre a lâmina, tornando-se progressivamente coalescentes e aglutinados, assumindo aspecto granular, isidióide ou pustular, com sorédios granulares gradualmente corticados. Pústulas e isídios verdadeiros ausentes. Medula branca, sem pigmentações. Lado de baixo negro, lustroso, liso ou pouco rugoso, com partes livres de rizinas. Margem marrom a mar- 
rom clara, lustrosa, $3,0-11,0 \mathrm{~mm}$, atenuada, lisa a rugosa, nua. Rizinas concoloridas, simples, raramente furcadas ou irregulares, $0,20-0,70(-1,40) \quad 0,05-0,10 \mathrm{~mm}$, poucas a freqüentes, agrupadas. Apotécios não encontrados. Picnídios não encontrados.

Substâncias de importância taxonômica: atranorina (córtex superior) e ácido lecanórico (medula).

Material estudado: BRASIL. São Paulo: Itanhaém, Balneário Santa Cruz, 14/I/2004, M.N.Benatti et al. 1729 (SP). Praia Grande, Bairro Cidade Ocean, 27/IX/1992, M.P.Marcelli \& O.Yano 14345, 14354, 14374 (SP); idem, na entrada da cidade, 20/V/1994, M.P.Marcelli 27196 (SP). São Sebastião, Centro de Biologia Marinha da USP, 18-III1988, M.P.Marcelli 2177, 2188 (SP).

Distribuição: América do Sul. Brasil: SP (Marcelli et al. 2007).

Comentários: Parmotrema eitenii é caracterizada pela formação de sorais marginais ou em ápices de dobras do talo tornando-se laminais, compostos por sorédios granulares que posteriormente tornam-se corticados formando aglomerações compactas e aglutinadas, grosseiras ou de aspecto isidióide.

Vários trabalhos (Hale 1965; Swinscow \& Krog 1988; Fleig 1997; Ribeiro 1998; Brodo et al. 2001; Eliasaro 2001; Donha 2005) mencionam variações para os propágulos vegetativos de $P$. tinctorum, a espécie mais similar, que vão desde isidiados e cilíndricos a até soredióides e grosseiros. Comparações quanto ao grau de variação do formato dos propágulos de P. tinctorum possibilitaram separar parte dos espécimes em grupos de espécies distintos, caracterizados pela formação e disposição dos propágulos, um pela formação de sorédios (P. eitenii) e outro pela formação de isídios (P. tinctorum).

Os espécimes mais comuns reconhecidos como $P$. tinctorum senso stricto são mais acinzentados, e têm lobos mais largos e arredondados que em P. eitenii. Formam somente isídios laminais cilíndricos de ápices escurecidos e não ornamentados, quase que totalmente restritos às áreas centrais na maior parte dos talos. Em P. eitenii formam-se sorais marginais ou em ápices de dobras do talo, que se estendem por sobre a lâmina, coalescendo e com freqüência tornando-se corticados, compostos por sorédios granulares que não são originados a partir de isídios. Embora estas aglomerações possam em parte ascender lembrando o formato de isídios ou de pústulas irregulares, pode-se notar claramente que não se tratam de isídios cilíndricos verdadeiros como os observados nos espécimes de P. tinctorum senso stricto. sendo mais facilmente discerníveis em algumas partes da lâmina onde não se fundem.

Parmotrema austrosinense difere pelo talo mais membranáceo mais plano, lobos mais estreitos, margens bastante sinuosas nos lobos sorediados e pelos sorais finos lineares contínuos marginais compostos de sorédios farinhosos que nunca ficam corticados e que não aglutinam ou ascendem. Ainda $P$. austrosinense também apresenta uma diferenciação de cor nas margens inferiores de lobos sorediados (em geral branca, creme ou variegada), o que não ocorre em $P$. eitenii.

Parmotrema gibberosum Kurokawa (Kurokawa \& Moon 1998), diferencia-se pelos lobos bem menores (2,0-4,0 mm larg.), e pelo córtex superior muito enrugado e quebradiço, freqüentemente desprendendo-se e expondo partes da medula, com rugas formando pústulas verruciformes verdadeiras que abrem apicalmente sem contudo originar sorédios. Pode apresentar cílios bastante curtos e simples pelas margens, ainda que muito raros e esparsos. A medula é branca na porção superior e alaranjada na inferior, reagindo $\mathrm{K}+$ púrpura. A parte branca da medula reage $\mathrm{KC}+$ róseo e $\mathrm{P}+$ alaranjado, devido à presença do ácido protocetrárico.

Parmotrema eitenii foi recentemente descrita e, ainda que desconhecida fora do litoral paulista, provavelmente será encontrada em regiões costeiras e interior de outros Estados (Marcelli et al. 2007).

\section{Parmotrema flavescens (Kremp.) Hale, Phytologia} 28(4): 336. 1974.

Parmelia glaberrima var. flavescens Kremp., Flora 52: 223. 1869.

Fig. 3a-b

Talo sublobado, verde amarelado a amarelado pardo quando em herbário, até $31,0 \mathrm{~cm}$ diam., subcoriáceo a submembranáceo, saxícola. Lobos de ramificação irregular, (2,5-) 4,0-13,0 mm larg., de sobrepostos lateralmente a raramente amontoados nas partes centrais, pouco adnatos a pouco elevados, pouco adpressos, os ápices subarredondados, subplanos a subcôncavos quanto mais estreitos ou às vezes revolutos, tornando-se involutos quando isidiados, as margens subcrenadas a crenadas, pouco onduladas e pouco ascendentes, mais ascendentes nas partes entre os lobos, às vezes irregulares, incisas, sublacinuladas. Superfície contínua, raramente com poucas quebras irregulares surgindo em algumas partes do centro, lisa. Lacínulas curtas, planas, truncadas, $0,4-4,5 \mathrm{~mm} \times 0,3-1,5 \mathrm{~mm}$, simples a irregulares, poucas, ocasionais, marginais, às vezes isidiadas, lado de baixo concolorido à margem inferior, misturadas a pequenos lóbulos irregulares adventícios. Máculas ausentes. Cílios escassos, quase que ausentes na maior parte da margem raramente aumentando para freqüentes ou abundantes em alguns trechos, $0,20-2,20 \times$ ca $0,05 \mathrm{~mm}$, simples, espalhados pela margem. Sorais e pústulas ausentes. Isídios cilíndricos lisos, $0,05-0,40(-2,00) \times 0,05-0,10 \mathrm{~mm}$, na maioria simples a pouco ramificados, às vezes tornando-se bastante ramificados ou até coralóides, eretos, firmes ou às vezes caducos em alguns trechos, concoloridos ou de ápices marrons, a maioria não ornamentada ou raramente com ápices e/ou lados ciliados, marginais, às vezes avançando submarginais ou surgindo nos ápices de dobras do talo. Medula branca, sem pigmentações, às vezes manchada pela oxidação e hidrólise do ácido salazínico. Lado de baixo negro, lustroso, liso a pouco rugoso, papilado a pouco venado. Margem marrom, 

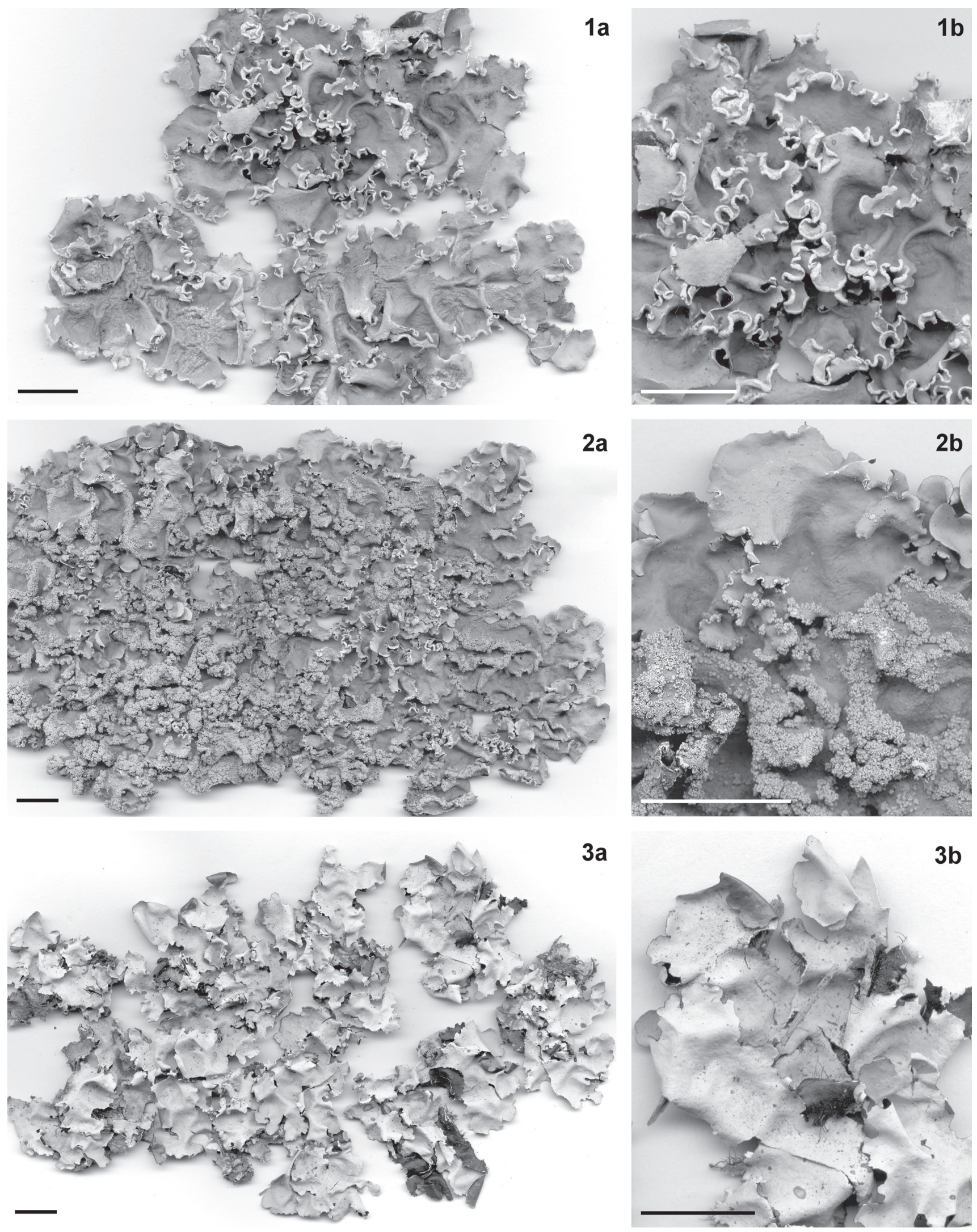

Figura 1. Parmotrema austrosinense (Zahlb.) Hale. a. Hábito. b. Detalhe (Marcelli 2314). Figura 2. Parmotrema eitenii Marcelli \& Benatti. a. Hábito. b. Detalhe (Marcelli 14345, holótipo). Figura 3. Parmotema flavescens (Kremp.) Hale. a. Hábito. b. Detalhe (Marcelli 23864). Escalas nas figuras $=1 \mathrm{~cm}$. 
às vezes castanha, lustrosa, $2,0-8,0 \mathrm{~mm}$, atenuada, lisa a pouco rugosa, raramente papilada, nua. Rizinas concoloridas, simples a raramente furcadas ou irregulares, $0,2-3,8 \mathrm{x}$ $0,05-0,10 \mathrm{~mm}$, freqüentes a abundantes, homogeneamente distribuídas a mais agrupadas em alguns trechos. Apotécios não encontrados. Picnídios submarginais, raros, de ostíolo negro. Conídios filiformes curtos, 6,5-9,0 x ca. 1,0 $\mu \mathrm{m}$.

Substâncias de importância taxonômica: atranorina (córtex superior), ácidos girofórico e salazínico (medula).

Material estudado: BRASIL. São Paulo: Peruíbe, R. E. Juréia-Itatins, Núcleo Guarauzinho, 27/VII/1993, M.P.Marcelli \& O.Yano 23718 (SP); idem, 29/VII/1993, M.P.Marcelli \& O.Yano 23861, 23864, 23868 (SP). São Sebastião, Centro de Biologia Marinha da USP, Ponta do Baleeiro, 19/III/1988, M.P.Marcelli 2245, 2247, 2248 (SP). Ubatuba, Ilha Anchieta, 23/XI/2003, A.A.Spielmann et al. 555 (SP); idem, 23/XI/2003, L.S.Canêz \& A.A.Spielmann 624.

Distribuição conhecida: América do Norte, América Central, e América do Sul. Brasil: MG, MS, RJ, RS e SP (Hale 1965; Fleig \& Riquelme 1991; Fleig 1995, 1997; Ribeiro 1998).

Comentários: Esta espécie saxícola é caracterizada pelo talo sublobado, coloração verde amarelada forte do córtex superior ( $\mathrm{K}-, \mathrm{KC}+$ amarelo, ácido úsnico), margens em geral densamente isidiadas, com isídios às vezes passando às áreas submarginais ou surgindo por sobre as dobras do talo, cílios marginais muito esparsos. O ácido girofórico é constatado em cromatografia, mas não reage positivamente nos testes de coloração tipo $\mathrm{C}$, devido ao ácido salazínico, cuja reação é mais evidente ( $\mathrm{K}+$ amarelo $\AA$ vermelho, $\mathrm{P}+$ amarelo, $\mathrm{UV}-$ ).

P. flavescens possui um talo bastante liso e contínuo. Os isídios são, na maioria, simples ou pouco ramificados atingindo não mais de $0,4 \mathrm{~mm}$ alt. em alguns talos, tornando-se maiores e mais ramificados em outros, chegando a até 2,0 $\mathrm{mm}$ de alt. Os estágios menores são observáveis nos talos com isídios mais desenvolvidos, e são nestes talos em que mais freqüentemente os isídios avançam margem adentro se tornando também submarginais. Os cílios marginais são muito esparsos; lobos jovens são geralmente eciliados nos ápices tornando-se ciliados nas partes mais velhas, ocasionalmente tornando-se mais abundante em trechos curtos. Embora sejam bastante raros no material estudado e quase não tenham sido mencionados na literatura, exceto por Hale (1965), cílios infreqüentes podem ser vistos nos ápices e laterais de alguns isídios, particularmente nos marginais.

Não foi encontrada nenhuma outra espécie cujas características principais se aproximassem das de $P$. flavescens, embora segundo Fleig (1997), P. delicatulum seja similar, ainda que não isidiada e de talo mais espesso. Hale (1965) cita para $P$. flavescens apotécios adnatos e raramente perfurados, contendo esporos 10,0-12,0 $\mu \mathrm{m}$ x 6,0-8,0 $\mu \mathrm{m}$. Apesar de citar picnídios em seu material, não encontrou conídios.

Dentre as espécies mais próximas estão $P$. xanthinum (Müll. Arg.) Hale, P. aberrans (Vain.) Canêz \& Marcelli e $P$. conformatum (Vainio) Hale. As duas primeiras (Hale 1965;
Nash \& Elix 2002) são caracterizadas pelos talos amarelados contendo ácido úsnico, com margens ciliadas e isidiadas; contudo, diferem de $P$. flavescens por serem corticícolas, terem margens e isídios mais freqüentemente ciliados, e pela química medular diferente, sendo que $P$. aberrans produz somente ácido girofórico $(\mathrm{C}+$ rosa, $\mathrm{KC}+$ rosa) na medula, enquanto que $P$. xanthinum produz somente ácidos graxos (C-, $\mathrm{KC}-$ ).

Parmotrema conformatum (Hale 1965; Ribeiro 1998) difere pela química medular contendo ácido protocetrárico $(\mathrm{KC}+$ róseo, $\mathrm{P}+$ alaranjado), pelos isídios mais finos e menos ramificados. Conforme cita Ribeiro (1998), esta espécie apresenta ainda lobos menores $(4,0-5,0 \mathrm{~mm})$ e cílios mais curtos $(0,5-1,0 \mathrm{~mm})$. Hale (1965) menciona material com os cílios no mesmo comprimento, mas com lobos um pouco mais largos e mais próximos dos encontrados em P. flavescens $(7,0-10,0 \mathrm{~mm})$.

Parmotrema neotropicum Kurok. difere pelo talo maculado efigurado, freqüentemente rachado, margens bem ciliadas, coloração cinzenta esverdeada (só atranorina), lado de baixo marrom a negro com rizinas dimórficas do centro até as bordas das margens dos lobos. Parmotrema fumarprotocetraricum Marcelli \& Hale é bem semelhante, diferindo pela presença do ácido fumarprotocetrárico na medula ( $\mathrm{K}+$ marrom, $\mathrm{P}+$ alaranjado).

\section{Parmotrema indicum Hale, Mycotaxon 5(2): 436. 1977.} Fig. 4a-b

Talo lobado, cinza esverdeado a cinza esverdeado pardo quando em herbário, $9,0 \mathrm{~cm}$ diam., subcoriáceo, corticícola. Lobos de ramificação irregular, 4,0-16,0 mm, de contíguos a sobrepostos lateralmente, pouco adnatos tornando-se pouco elevados quando sorediados, pouco adpressos, os ápices arredondados a subarredondados, subplanos a subcôncavos, as margens lisas a subcrenadas, subplanas nas partes distais tornando-se subascendentes ou involutas e um pouco mais sinuosas em direção ao centro e pregueadas subcanaliculadas nas axilas, inteiras. Superfície contínua, tornando-se pouco irregularmente quebrada nas partes velhas, lisa a pouco rugosa em alguns trechos. Lacínulas ausentes. Máculas ausentes. Cílios negros, simples, 0,10-1,10 (muito raro $-2,00)$ x ca. $0,05(-0,15) \mu \mathrm{m}$, quebradiços, espalhados pela margem porém raros e muito esparsos. Sorais lineares contínuos a interrompidos, marginais e estreitos, muito raramente surgindo subcapitados submarginais, com sorédios farinhosos. Pústulas e isídios ausentes. Medula branca, sem pigmentações. Lado de baixo negro, lustroso, liso ou pouco rugoso. Margem marrom, tornando-se creme quando em lobos sorediados, lustrosa a um pouco opaca, 3,0-10,0 $\mathrm{mm}$, atenuada quando marrom a nítida quando creme, lisa ou pouco rugosa, parte venada, nua. Rizinas concoloridas, simples, $0,20-1,80 \times 0,05(-0,20) \mathrm{mm}$, freqüentes, agrupadas, às vezes aglutinadas. Apotécios não encontrados. Picnídios submarginais, de ostíolo negro. Conídios filiformes ou raramente bacilariformes, $(6,0-) 8,0-14,0 \mathrm{x}$ ca. $1,0 \mu \mathrm{m}$. 
Substâncias de importância taxonômica: atranorina (córtex superior) e ácido girofórico (medula).

Material estudado: BRASIL. São Paulo: Praia Grande, Bairro Boqueirão, 27/IX/1992, M.P.Marcelli \& O.Yano 14379 (SP).

Distribuição: Ásia, África, América do Norte e América do Sul. Brasil: RS (Fleig 1997; Hale 1977; Krog \& Swinscow 1981; Kurokawa 1993).

Comentários: Esta espécie é caracterizada pelos sorais marginais lineares, margens ciliadas, medula contendo ácido girofórico e conídios filiformes. A descrição de $P$. indicum de Hale (1977) condiz bastante com o espécime estudado, exceto pela não detecção da substância norlobaridona na medula, sendo que ele não mencionou conídios em seu material.

Hale (1977) comparou P. indicum com P. sancti-angeli Lynge (Hale) e $P$. yodae (Kurok.) Hale, diferenciando-a pela combinação de ácido girofórico e norlobaridona, conhecida à época somente para $P$. balense (Winnem) Hale, que segundo o autor é bem mais coriácea e tem córtex superior muito maculado.

Krog \& Swinscow (1981) descreveram Parmelia indoafra Krog \& Swinscow confirmando a presença das mesmas substâncias citadas por Hale, como um nom. nov. para Parmotrema indicum, estendendo a distribuição de $P$. indoafra para o leste africano. Comparando-se com a descrição de Hale (1977), esta espécie foi descrita com lobos um pouco mais largos $(1,0-2,0 \mathrm{~cm})$ e cílios mais longos $(-3,0 \mathrm{~mm})$. Os conídios foram descritos como filiformes, 10,0-12,0 $(-14,0) \mu \mathrm{m}$ comp.

Os demais aspectos verificados por Hale (1977) permaneceram os mesmos na descrição de Krog \& Swinscow (1981). Anos depois, Swinscow \& Krog (1988) reconheceram o gênero Parmotrema e citaram então a espécie como $P$. indicum, mas sem quaisquer alterações ou comentários a respeito.

Fleig (1997) citou espécimes de $P$. indicum com a mesma largura de lobos do material do leste africano, contendo cílios do mesmo tamanho observado por Hale (1977), sem ocasionalmente excederem estas medidas como acontecia com o material de Swinscow \& Krog (1988). A liquenóloga Mariana Fleig foi a primeira autora a referir e comentar sobre a variação na espessura dos cílios. Nosso espécime é semelhante ao descrito por esta autora, exceto pela coloração e espessura (parcial) dos sorais, pela granulação dos sorédios, e pela presença de norlobaridona medular também confirmada em seu trabalho.

Com exceção das diferenças nos cílios e conídios, $P$. indicum é consideravelmente difícil de separar de $P$. sanctiangeli (Lynge) Hale. Spielmann (2005) mencionou espécimes de $P$. indicum similares aos de Fleig (1997), porém com cílios mais freqüentemente ramificados. Segundo o autor, $P$. indicum poderia ser separada de $P$. sancti-angeli, por apresentar um talo mais robusto e subcoriáceo, com lobos mais adnatos e sorais marginais normalmente largos ou às vezes orbiculares e laminais em lobos mais velhos. Já P. sanctiangelii teria um talo mais delicado e membranáceo, com lobos mais amontoados e ascendentes, e sorais marginais mais estreitos sem apresentar sorais orbiculares laminais.

Spielmann (2005) não encontrou norlobaridona em seus espécimes. Diferenças de seu material para com o nosso restringem-se à ramificação e comprimento de cílios, à granulação dos sorédios e à espessura de sorais. Os conídios citados pelo autor são similares, $8,0-12,5 \mu \mathrm{m}$ compr. (Spielmann 2005).

Concordamos que há divergências entre o material analisado e a literatura sobre a granulação dos sorédios, espessura dos sorais, freqüência e ramificação de cílios e a ausência de norlobaridona medular. Entretanto, também há divergências quanto às mesmas características entre os trabalhos mencionados (Hale 1977, Krog \& Swinscow 1981, Swinscow \& Krog 1988; Fleig 1997; Spielmann 2005).

A espécie mais freqüentemente comparada com $P$. indicum é $P$. sancti-angeli. Esta pode ser diferenciada pelos lobos sorediados mais elevados, cílios marginais abundantes, mais longos (às vezes $+5,0 \mathrm{~mm}$ comp.) e ascendentes, e conídios sublageniformes e menores $(5,0-8,0 \mu \mathrm{m})$. Ainda segundo Hale (1960; 1965) e Sipman (2004), espécimes de P. sanctiangeli podem ocasionalmente apresentar pigmento alaranjado $\mathrm{K}+$ (rodoficina) na medula, mas que não foi encontrado em nenhum espécime do litoral. Fleig (1997) distinguiu $P$. indicum de $P$. sancti-angeli pelo talo mais robusto e coriáceo, sorédios mais granulares com coloração geralmente igual a do talo e conídios filiformes 8,0-14,0 $\mu \mathrm{m}$.

Parmotrema permutatum (Stirton) Hale é diferenciada pela coloração da medula, cuja porção inferior é sempre pigmentada. Os conídios vistos no material de P. permutatum são menores, embora Fleig (1997) tenha mencionado conídios maiores, e Canêz (2005) conídios um pouco menores (ver comentários em P. permutatum). As margens de $P$. permutatum são também bastante ciliadas, como em P. sancti-angeli.

Parmotrema subarnoldii (Abbayes) Hale e P. rampoddense (Nyl.) Hale diferem pela química medular: ácido protocetrárico na primeira $(\mathrm{C}-, \mathrm{KC}+$ róseo, $\mathrm{P}+$ alaranjado, $\mathrm{UV}-)$ e ácido alectorônico na segunda $(\mathrm{C}-, \mathrm{KC}+$ róseo, $\mathrm{P}-$, UV+ azul-esverdeado). Ambas são também bastante ciliadas e com cílios longos, próximos do tamanho e formato encontrado em $P$. sancti-angeli.

Parmotrema ciliiferum Hale tem sorais quase sempre nos ápices de lacínulas, e contém ácido constipático e alguns outros ácidos graxos medulares (todos os testes de coloração negativos).

Parmotrema indicum é uma recente nova citação para o Estado de São Paulo (Benatti 2005). Entretanto, problemas com as descrições de materiais atribuídos a esta espécie e novas descobertas em outras localidades do Estado indicam a possibilidade de haver mais de um táxon envolvido sob este nome, não sendo improvável que o material do litoral possa ser um novo táxon de morfologia e química próximas. 


\section{Parmotrema permutatum (Stirton) Hale, Phytologia} 28(4): 338. 1974.

Parmelia permutata Stirton, Scottish Naturalist 4: 252. 1877-78.

Fig. 5a-b7

Talo lobado a sublobado, cinza esverdeado a pardo quando em herbário, até $11,0 \mathrm{~cm}$ diam., subcoriáceo, corticícola. Lobos de ramificação irregular, (2,0-) 3,0-14,0 mm, contíguos a sobrepostos lateralmente, pouco amontoados no centro, adnatos a pouco elevados, às vezes involutos ou revolutos quando sorediados, adpressos a pouco adpressos, os ápices subarredondados, de subplanos à subcôncavos, as margens lisas a subcrenadas, levemente onduladas a mais sinuosas quando sorediadas, inteiras ou em parte pouco incisas, sublacinuladas. Superfície lisa e contínua nas partes distais tornando-se irregularmente quebrada e um pouco enrugada nas partes velhas. Lacínulas curtas, planas, truncadas, 0,2-1,1 $(-1,8)$ x 0,2-0,9 $(-1,1) \mathrm{mm}$, simples, de superfície contínua nas partes distais tornando-se irregularmente quebrada nas partes velhas, lisa, pouco enrugada nas partes velhas, espalhadas por quase toda a margem porém mais freqüentes no centro do talo do que nos lobos mais jovens, lado de baixo geralmente creme. Máculas ausentes. Cílios negros, simples, $0,1-2,5(-3,0)$ x ca. $0,05 \mathrm{~mm}$, de poucos a freqüentes, distribuídos por toda a margem. Sorais subcapitados nos ápices das lacínulas marginais e às vezes capitados em áreas submarginais, menos freqüentemente lineares interrompidos surgindo em lobos jovens pouco sinuosos, parcialmente coalescentes e aglutinados de aspecto irregular, sorédios farinhosos, às vezes enegrecidos. Pústulas e isídios ausentes. Medula com camadas de cores diferentes, branca na parte superior, salmão, ocre e amarelada na parte inferior. Lado de baixo negro, lustroso, liso a rugoso, em parte venado ou pouco papilado. Margem marrom, tornando-se creme ou variegada quando em lobos lacinulados e sorediados, lustrosa, 2,0-8,0 mm, nua, atenuada quando marrom a nítida quando creme, lisa a pouco rugosa, às vezes venada ou em parte pouco papilada na área de transição para o centro. Rizinas concoloridas, na maioria simples, em parte furcadas ou irregulares, $0,20-2,10 \times 0,05-0,10(-0,15) \mathrm{mm}$, poucas a freqüentes, raramente abundantes em alguns pontos, em parte aglutinadas, agrupadas. Apotécios ausentes. Picnídios submarginais, às vezes escassos, de ostíolo negro, conídios baciliformes a curto filiformes, $6,0-10,0 \mathrm{x}$ ca. $1,0 \mu \mathrm{m}$.

Substâncias de importância taxonômica: atranorina (córtex superior), ácido girofórico e pigmentos tipo eumitrina (medula).

Material estudado: BRASIL. São Paulo: Praia Grande, Bairro Cidade Ocean, 4/VII/1988, M.P.Marcelli \& J.Vieira Filho 3018 (SP); idem, 6/VII/1988, M.P.Marcelli \& J.Vieira Filho 3048, 3106A, 3106B, 3107, 3109, 3110 (SP).

Distribuição: Oceania, Ásia, África, América Central, Caribe e América do Sul. Brasil: PR, RS e SP (Fleig 1997; Hale 1965; Marcelli 1990; Krog \& Swinscow 1981).
Comentários: Parmotrema permutatum é caracterizada pela medula com camadas de cores diferentes (branca na parte superior, tendo logo abaixo uma camada pigmentada de múltiplas cores na metade inferior), margens ciliadas, sorais lineares marginais ou nos ápices de lacínulas e rizinas agrupadas no córtex inferior. Os pigmentos devem se tratar de eumitrinas, como descritos por Louwhoff \& Elix (1999).

A maioria das descrições encontradas (Elix 1994; Krog \& Swinscow 1981; Kurokawa \& Lai 2001; Louwhoff \& Elix 1999; Swinscow \& Krog 1988) refere-se a três colorações na porção inferior da medula, todas percebidas no material estudado (amarela, salmão e ocre), ainda que Krog \& Swinscow (1981) não mencionaram uma porção superior branca. Em nossos espécimes a parte pigmentada pode ter uma coloração na porção próxima à parte branca da medula e outra na parte próxima do córtex inferior, notando-se com freqüência o aparecimento de três cores distintas dependendo do ponto observado do talo, sendo que em alguns espécimes evidencia-se mais a cor salmão do que a amarela.

Observando-se a medula, nota-se que uma cor gradualmente cede lugar a outra. As áreas de cor ocre, à primeira vista semelhantes ao pigmento esquirina, reagem da mesma tonalidade que as demais partes coloridas da medula em testes de K. As reações de coloração e a composição química são as mesmas citadas em Eliasaro (2001) e bastante parecidas com as de Fleig (1997), Canêz (2005) e Donha (2005). Nenhum tipo de pigmentação $\mathrm{K}+$ é citado para P. permutatum.

A diferenciação de camadas é observada com nitidez expondo a medula até sua porção inferior. Apenas as partes distais têm coloração branca (superior) e amarela (inferior) na proporção 1:1. Porém, em direção ao centro, vão surgindo gradativamente as cores róseo salmão e finalmente ocre, sendo que a parcela colorida da medula pode compor a maior parte da mesma em alguns trechos do talo.

Fleig (1997) descreveu espécimes de P. permutatum com conídios baciliformes a filiformes $8,5-13,5 \mu \mathrm{m}$ comp. Canêz (2005) citou um espécime com conídios baciliformes menores que os mencionados por Fleig (1997), medindo 7,5-8,7 $\mu \mathrm{m}$ compr., mais próximos aos observados aqui, entretanto mencionando que o espécime apresentava medula apenas amarela clara na porção inferior. Donha (2005) também descreveu $P$. permutatum com medula branca na porção superior e amarela na inferior, com conídios $8,0-14,0 \mu \mathrm{m}$ compr. e uma descrição mais semelhante à de Fleig (1997).

Apenas Fleig (1997) e Canêz (2005) citaram presença de ácido secalônico medular em espécimes de P. permutatum. O estudo do material tipo e de mais material atribuído à espécie pode vir a revelar quais espécimes sejam de fato $P$. permutatum e quais poderiam se tratar de uma espécie desconhecida. A dúvida quanto ao material com apenas duas cores medulares e ácido secalônico é devida ao fato de que todas as demais citações de $P$. permutatum anteriores a Louwhoff \& Elix (1999) mencionam "pigmentos desconhecidos", sendo que os ácidos secalônicos já eram conhecidos à época de suas publicações. 
Normalmente as descrições de $P$. permutatum mencionam as mesmas cores vistas aqui, incluindo materiais de localidades próximas àquela onde o tipo foi coletado. Consideramos que a espécie tenha algo como uma medula bicamada, onde a porção inferior apresente uma variação de tonalidades a partir da diferenciação da pigmentação. Não foram encontrados espécimes com uma medula somente bicolor.

Parmotrema conjunctum Hale difere pelos sorais marginais lineares mais discretos que os de $P$. permutatum e pela medula totalmente amarela contendo liquexantona (UV+ amarelo-dourado) e ácido girofórico (Hale 1974, Fleig 1997). Segundo Hale (1974), P. conjunctum apresenta pigmentação medular quase idêntica (em TLC) à encontrada em P. endosulphureum (Hillmann) Hale, o que inclui ácido secalônico.

Parmotrema sancti-angeli difere por apresentar sorais marginais mais contínuos e com sorédios sempre claros, talo mais membranáceo, e medula totalmente branca às vezes com manchas de pigmento $\mathrm{K}+$ avermelhado. Os conídios de $P$. sancti-angeli são ainda sublageniformes muito curtos, medindo geralmente entre $6,0-8,0 \mu \mathrm{m}$.

\section{Parmotrema sancti-angeli (Lynge) Hale, Phytologia 28(4): 339. 1974.}

Parmelia sancti-angeli Lynge. Arkiv för Botanik 13:35. 1914 Fig. 6a-b

Talo lobado às vezes parcialmente sublobado, cinza esverdeado a cinza esverdeado escuro e pardo quando em herbário, até $24,0 \mathrm{~cm}$ diam., submembranáceo a subcoriáceo, ramulícola ou corticícola. Lobos de ramificação irregular, (2,0-) 3,5-16,5 mm larg., de contíguos a sobrepostos lateralmente ou às vezes amontoados, de adnatos e pouco adpressos a elevados e soltos quando sorediados, os ápices arredondados a subarredondados, planos a subcôncavos, às vezes revolutos quando sorediados, as margens lisas a crenadas, subplanas nas partes distais a ascendentes, involutas ou revolutas conforme tornam-se sorediadas, progressivamente mais sinuosas em direção ao centro. Superfície contínua e lisa tornando-se irregular ou transversalmente quebrada e às vezes pouco rugosa nas partes velhas. Lacínulas ausentes. Máculas ausentes a fracas e raras, lineares, laminais, originadas por quebras. Cílios negros, simples ou às vezes furcados, $0,30-4,40(-5,80) \times 0,05-0,10 \mu \mathrm{m}$, freqüentes a abundantes, distribuídos por toda a margem, porém gradativamente mais escassos ao ponto desaparecerem em vários trechos pelo surgimento dos sorais. Sorais lineares contínuos a interrompidos, marginais e estreitos a pouco alargados quando nos lobos mais velhos e muito raramente subcapitados submarginais, sorédios farinhosos, subgranulares em lobos mais velhos, algumas vezes escurecidos. Pústulas e isídios ausentes. Medula branca, sem pigmentações. Lado de baixo negro, lustroso, liso a rugoso, em parte venado. Margem marrom a marrom clara, tornando-se creme, bran- ca ou variegada em lobos sorediados, lustrosa a um pouco opaca, $3,0-10,0 \mathrm{~mm}$, atenuada quando marrom a nítida quando creme ou branca, lisa a rugosa, às vezes venada, nua. Rizinas na maior parte concoloridas, ocasionalmente marrons ou creme em áreas do centro, ou ainda negras ou brancas na parte de transição entre o centro e a margem, simples a menos freqüentemente furcadas ou irregulares, $0,30-3,20 \times 0,05-0,10(-0,15) \mathrm{mm}$, poucas a freqüentes, às vezes mais abundantes em alguns pontos, agrupadas. Apotécios ausentes. Picnídios submarginais a subapicais, de ostíolo negro, conídios sublageniformes, 5,0-8,0 $(-9,0)$ $\mathrm{x}$ ca. $1,0 \mu \mathrm{m}$.

Substâncias de importância taxonômica: atranorina (córtex superior) e ácido girofórico (medula).

Material estudado: BRASIL. São Paulo: Ilha Comprida, 2/IV/2004, A.A.Spielmann et al. 800 (SP). Itanhaém, Estância Santa Cruz, 10/II/2004, M.P.Marcelli et al. 36208 (SP). Praia Grande, Bairro Cidade Ocean, 4/VII/1988, M.P.Marcelli \& J.Vieira Filho, 3013, 3020, 3023, 3032, 3033 (SP); idem, 6/VII/1988, M.P.Marcelli \& J.Vieira Filho 3055 , 3058, 3063, 3067 (SP); idem, 14/VII/1988, M.P.Marcelli \& O. Yano 3405 (SP); idem, 7/I/1989, M.P. Marcelli et al. 4077, 4084, 4085, 4093, 4094, 4096 (SP).

Distribuição: Oceania, Ásia, África, América do Norte, América Central, Caribe, América do Sul. Brasil: MG, MT, PR, RS, SC e SP (Elix 1994; Fleig 1997; Hale 1965; Krog \& Swinscow 1981; Louwhoff \& Elix 1999; Ribeiro 1998).

Comentários: Esta espécie é caracterizada pelos lobos largos, sorais marginais lineares estreitos, margens com cílios bastante longos às vezes com mais de $5,0 \mathrm{~mm}$ compr. freqüentemente ascendentes, conídios sublageniformes medindo 5,0-9,0 $\mu \mathrm{m}$, e ácido girofórico medular $(\mathrm{C}+\mathrm{e} \mathrm{KC}+$ róseo ou avermelhados).

Hale (1965) mencionou apotécios adnatos com esporos 13,0-18,0 $\mu \mathrm{m}$ compr. de epispório fino $(1,0 \mu \mathrm{m})$, enquanto que Lynge (1914) mencionou esporos bem maiores medindo entre 26,0-36,0 $\mu \mathrm{m}$ com epispório espesso ("late limbatae"). Ao estudar os espécimes analisados por Lynge (1914) para tipificação, Hale (1960) percebeu uma variedade muito grande, incomum e difícil de ser correlacionada devido à ausência de material fertil da espécie, citando esporos em material tropical com não mais que $16,0 \mu \mathrm{m}$ de tamanho.

Entretanto, Winnem (1975) afirmou que o apotécio no material tipo de $P$. sancti-angeli pertencia na verdade a outra espécie, P. subrugatum (Krempelhuber) Hale. A afirmação de Hale (1960) de ter encontrado espécimes de $P$. sancti-angeli com esporos de tamanhos muito variados não persistiu até seu trabalho com as espécies de Amphigymnia (Hale 1965), sendo que ele não explicou ou deixou transparecer se parte do material identificado à época da revisão do material estudado por Lynge (1914), especialmente o que possui esporos maiores, tratava-se de alguma outra espécie, ao mencionar um tamanho menor de esporos em sua descrição de $P$. sancti-angeli. Fleig (1997) afirmou que os poucos apotécios dos espécimes de $P$. sancti-angeli encontrados por ela são 

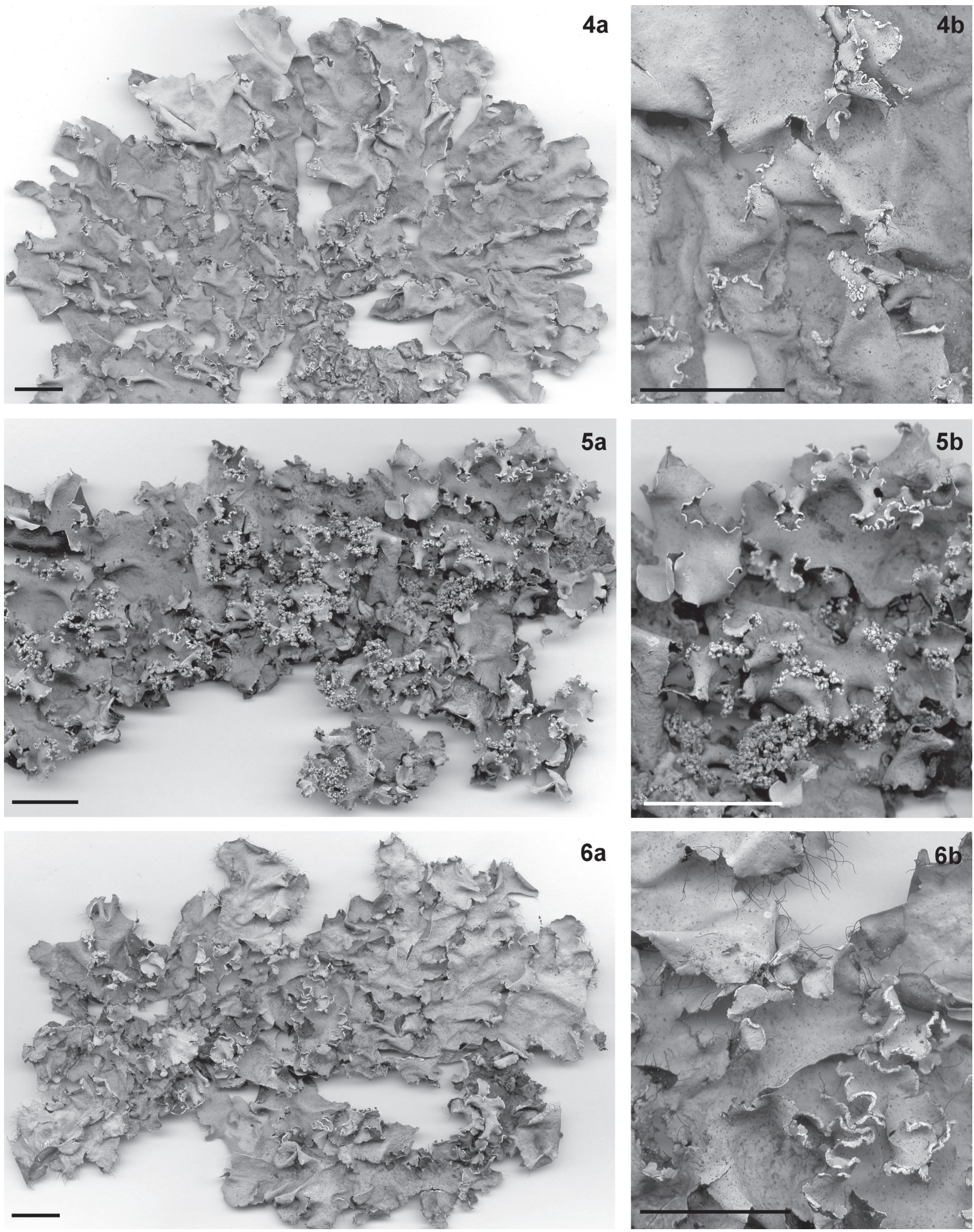

Figura 4. Parmotrema indicum Hale. a. Hábito. b. Detalhe (Marcelli 14379). Figura 5. Parmotrema permutatum (Stirton) Hale. a. Hábito. b. Detalhe (Marcelli 3110). Figura 6. Parmotema sancti-angeli (Lynge) Hale. a. Hábito. b. Detalhe (Marcelli 3033). Escalas nas figuras $=1 \mathrm{~cm}$. 
perfurados, embora tanto Lynge (1914) quanto Hale (1965) contradigam esta afirmação.

Em P. sancti-angeli é comum o surgimento de rizinas não concoloridas ao córtex inferior, marrons ou cremes no centro ou então negras e brancas próximo à área de transição das margens para o centro. Outra característica é a relação dos cílios com os sorais, onde é perceptível que lobos não sorediados são mais densamente ciliados. Acompanhandose os sorais das partes jovens ao centro do talo, conforme estes vão se adensando e cobrindo uma porção maior das margens os cílios gradualmente desaparecem, restringindose a pequenos intervalos entre os sorais, ao ponto de desaparecerem quase por completo nos lobos mais densamente sorediados, onde os sorais coalescem ficando quase que contínuos. Os poucos cílios que aparecem nestas partes são quase que imperceptíveis a olho nu.

Apesar da distribuição linear marginal dos sorais ser a predominante em $P$. sancti-angeli, sorais orbiculares laminais ocasionais também puderam ser constatados em vários espécimes estudados.

Segundo Hale (1965), as espécies mais parecidas com $P$. sancti-angeli são $P$. rampoddense (Nylander) Hale e $P$. subarnoldii (Abbayes) Hale. Ambas diferem de P. sanctiangeli pela química, que apresenta ácido alectorônico em $P$. rapoddense ( $\mathrm{KC}+$ róseo, $\mathrm{UV}+$ azul-esverdeado) e ácido protocetrárico em $P$. subarnoldii ( $\mathrm{KC}+$ róseo, $\mathrm{P}+$ alaranjado). Os conídios também são diferentes em $P$. rampoddense, sendo filiformes mais longos medindo entre $9,0-12,0 \mu \mathrm{m}$ (Fleig 1997).

Parmotrema permutatum (Stirton) Hale é também ciliada, sorediada e apresenta ácido girofórico na medula. Entretanto, tem a medula normalmente com duas a três cores devido aos pigmentos do tipo eumitrinas, além de ter conídios filiformes curtos $6,0-10,0 \mu \mathrm{m}$ compr.

Parmotrema indicum Hale é talvez a espécie mais difícil de se separar de P. sancti-angeli, tanto pela disposição dos sorais como pela química. Devido às dificuldades em separar as duas quando na ausência de conídios, Spielmann (2005) descreveu que peculiaridades relacionadas aos cílios e aos sorais poderiam representar diferenças consistentes elas: os cílios de $P$. indicum seriam um tanto mais espessos e freqüentemente mais ramificados que os de $P$. sancti-angeli, em geral mais finos $(0,05-0,10 \mathrm{~mm})$ e bem menos vezes ramificados. Ainda segundo o autor, os sorais de $P$. indicum são normalmente mais largos que os de $P$. sancti-angeli, por vezes até orbiculares e laminais quando em lobos mais velhos.

Talos de $P$. indicum são citados por Spielmann (2005) como mais robustos e subcoriáceos e com lobos mais adnatos que os de $P$. sancti-angeli. O espécime de $P$. indicum descrito aqui é quase idêntico aos de $P$. sancti-angeli, exceto pelo talo mais coriáceo, cílios mais curtos e esparsos e conídios filiformes medindo 8,0-14,0 $\mu \mathrm{m}$ comp. Este espécime é também similar aos descritos por Fleig (1997) e Spielmann (2005), tendo conídios com a mesma forma e medidas citadas por ambos os autores.
Não foi detectada a presença medular de norlobaridona no espécime estudado, substância também não constatada por Spielmann (2005) em seu material, proveniente de barrancos e peraus da encosta da Serra Geral na região central do Estado do Rio Grande do Sul.

Nenhum espécime analisado apresentou pigmentação na medula, embora Hale (1965) afirme ter encontrado em metade dos espécimes estudados em seu trabalho, mas afirmando que o holótipo de $P$. sancti-angeli não apresenta o pigmento. Ele confirmou também ter encontrado este pigmento no holótipo de Parmelia pseudohyporysalea Asahina, único sinônimo aceito para $P$. sancti-angeli. Segundo Hale (1965), o pigmento de cor amarelo-alaranjado encontrado trata-se de rodoficina ( $\mathrm{K}+$ púrpura).

\section{Parmotrema tinctorum (Nylander) Hale, Phytologia} 28(4): 339. 1974.

Parmelia tinctorum Nylander, Flora 55: 547. 1872. Fig. 7a-b

Talo lobado, cinza esverdeado a pardo quando em herbário, até $12,0 \mathrm{~cm}$ diam, subcoriáceo a coriáceo, corticícola. Lobos de ramificação irregular, (3,0-) 5,0-18,0 (-25,0) mm larg., sobrepostos lateralmente tornando-se amontoados em direção ao centro, pouco adnatos a elevados, adpressos a pouco adpressos, os ápices arredondados a subarredondados, côncavos a subcôncavos, menos freqüentemente subplanos, as margens lisas, às vezes subcrenadas pelo surgimento de isídios, pouco a não onduladas, subplanas a ascendentes e involutas, tornando-se freqüentemente pregueadas e subcanaliculadas entre os lobos em talos maiores, inteiras. Superfície contínua, com poucas quebras, lisa a pouco rugosa. Lacínulas ausentes, às vezes aparecendo lóbulos jovens adventícios em partes velhas, simples, arredondados, subplanos a subcôncavos, 1,0-5,5 x 1,0-3,5 $\mu \mathrm{m}$, lado de baixo concolorido à margem inferior. Máculas ausentes. Cílios ausentes. Sorais e pústulas ausentes. Isídios cilíndricos lisos, 0,05-0,45 x 0,05-0,10 mm, simples a pouco ramificados, ocasionalmente muito ramificados ou coralóides, eretos, retos a tortuosos, firmes, concoloridos ou de ápices marrons, não ornamentados ou às vezes de ápices decorticados, mais comuns em ápices de dobras a laminais, menos freqüentes marginais em lobos mais velhos. Medula branca, sem pigmentações. Lado de baixo negro, lustroso, liso a pouco rugoso, às vezes pouco venado, com partes livres de rizinas. Margem marrom a marrom clara, lustrosa, 2,0-10,0 mm, atenuada, lisa a pouco rugosa, nua. Rizinas concoloridas, simples a raramente furcadas ou irregulares, $0,20-0,60(-2,50) \times 0,05-0,10$ $(0,15) \mathrm{mm}$, poucas a freqüentes, agrupadas. Apotécios raros, côncavos, $0,5-8,6 \mathrm{~mm}$, submarginais, pedicelados, margem lisa a isidiada e crenada pela formação de isídios, anfitécio e pedicelo lisos quando jovens, isidiados tornando-se rugosos e mais isidiados conforme envelhecem, disco marrom, não pruinoso, imperfurado quando jovem a fendido e raramente perfurado quando velho, esporos elipsóides, 12,5-17,0 x 

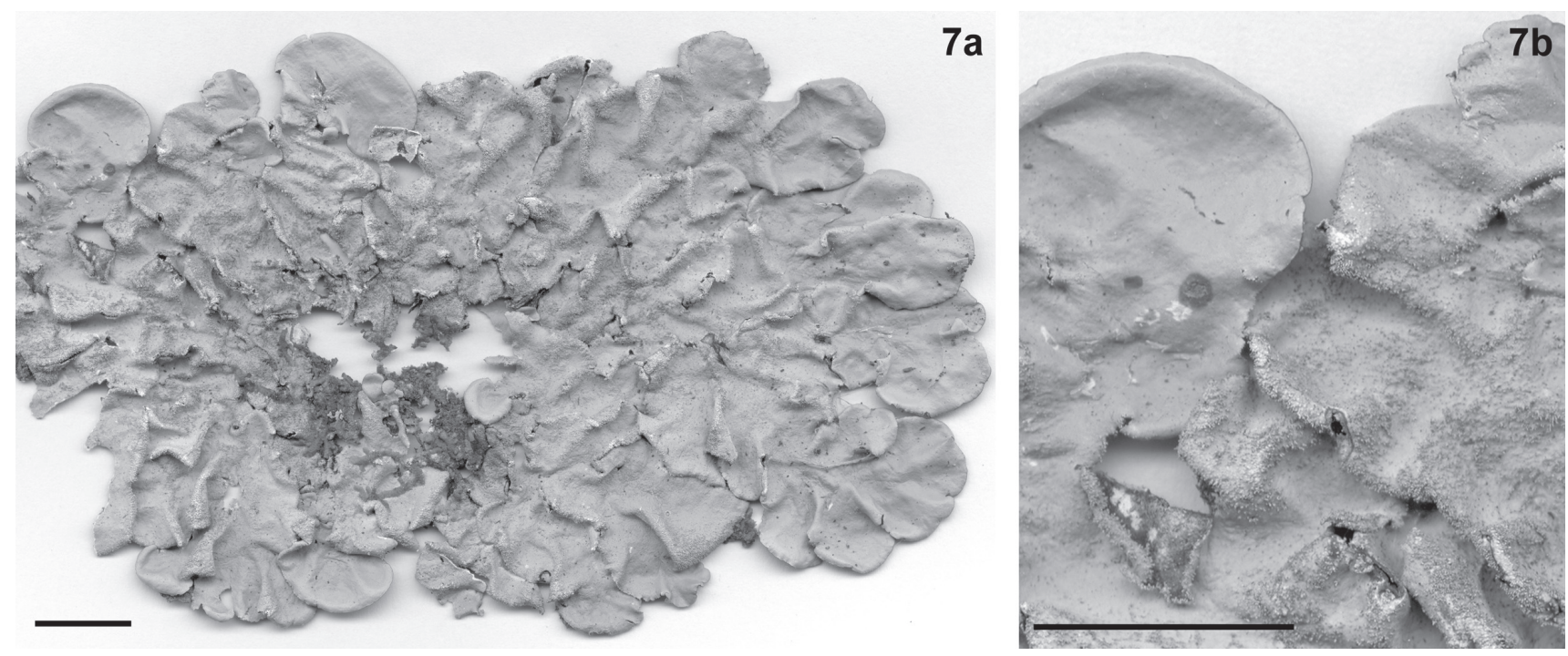

Figura 7. Parmotrema tinctotum (Nyl.) Hale. a. Hábito. b. Detalhe (Benatti 1724). Escalas nas figuras $=1 \mathrm{~cm}$.

6,5-7,5 $\mu \mathrm{m}$, epispório ca. 1,0 $\mu \mathrm{m}$. Picnídios raros e muito escassos, submarginais, de ostíolo negro, conídios filiformes, $10,0-15,0 \mathrm{x}$ ca. $1,0 \mu \mathrm{m}$.

Substâncias de importância taxonômica: atranorina (córtex superior) e ácido lecanórico (medula).

Material estudado: BRASIL. Rio Grande do Sul: Tapes, Lagoa dos Patos, 29/I/1994, M.P.Marcelli et al. 26520, $26521 B$ (SP). São Paulo: Ilha Comprida, área central da ilha, 2/IV/2004, M.N.Benatti et al. 1736 (SP). Itanhaém, Balneário Santa Cruz, 14/I/2004, M.N.Benatti et al. 1724 (SP). Praia Grande, Bairro Cidade Ocean, 7/I/1989, M.P.Marcelli et al. 4121 (SP). São Sebastião, Centro de Biologia Marinha da USP, 18/III/1988, M.P.Marcelli 2194, 18110 (SP); idem, 19/III/1988, M.P.Marcelli 2326 (SP). Ubatuba, Ilha Anchieta, 22/XII/2003, A.A.Spielmann et al. 594 (SP); idem, 22/ XII/2003, L.S.Canêz \& A.A.Spielmann 643 (SP).

Distribuição: Oceania, Ásia e Pacífico Norte, África, América do Norte e Atlântico Norte, América Central, Caribe, e América do Sul. Brasil: MG, MS, MT, PA, PR, RJ, RS, SC e SP (Brako et al. 1985; Culberson et al. 2005; Elix 1994; Feuerer 2005; Fleig 1997; Fleig \& Riquelme 1991; Hale 1965; Krog \& Swinscow 1981; Osorio 1972; Osorio 1977).

Comentários: Parmotrema tinctorum é uma das espécies mais comuns do gênero, encontrada nas áreas tropicais do mundo. É caracterizada pelos talos de lobos largos e arredondados, ausência de cílios nas margens, lâmina bastante isidiada principalmente nas partes centrais e presença de ácido lecanórico ( $\mathrm{C}+\mathrm{e} \mathrm{KC}+$ avermelhados) na medula.

Comparando o material estudado ao descrito na literatura (Hale 1965; Swinscow \& Krog 1988; Fleig 1997; Ribeiro 1998; Brodo et al. 2001; Eliasaro 2001; Donha 2005), percebeu-se que os espécimes atribídos à $P$. tinctorum possuem grande similaridade morfológica, exceto pela variação de formas dos isídios. Fleig (1997) por exemplo, citou que aproximadamente metade de seus espécimes apresentavam "isidios preferentemente granulares", comparados aos demais que apresentavam "isídios finos, grosseiros, ou ainda grânulos originados de papilas às vezes com isídios robustos e inflados".

Uma vez que foi possível discernir grupos diferentes dentro de P. tinctorum, o grupo que apresentava apenas sorédios (P. eitenii) foi considerado uma espécie à parte do grupo que apresenta apenas isídios, uma vez que esta diferenciação é normalmente aceita em nível específico com liquens. Não foram encontrados espécimes intermediários entre os dois grupos, ou mesmo menções na literatura citada para espécimes que apresentassem as duas formas de propagação para um mesmo talo. Nas descrições há menções para isídios às vezes soredióides ou pustulares, mas não sorédios verdadeiros em origem. Estas são próximas do que foi observado nos espécimes de P. eitenii, que apresenta formação de sorais granulares que podem ou não assumir aspecto isidióide ou pustular conforme se desenvolvem, facilmente percebido quanto à origem ao se observar das partes distais para as centrais do talo.

Nos espécimes aqui aceitos como P. tinctorum senso stricto, foi encontrada somente formação de isídios verdadeiros, que não originam e que não estão misturados a sorédios ou a qualquer outra estrutura soredióide. Estes são constantes no formato e na distribuição, que geralmente se restringe à área central do talo, com as partes distais quase sempre desprovidas de isídios. Isídios marginais são muito raros no material observado, estando também restritos às porções centrais e em geral bem velhas dos talos.

Os isídios em $P$. tinctorum variam quanto à ramificação. Os padrões mais comuns encontrados vão do totalmente simples, passando por simples a pouco ramificados a até simples a ramificados raramente coralóides. Coloração e espessura são similares em todos, sendo que parte dos isídios mais ramificados em alguns espécimes tem ápices decorticados, alguns desde jovens. Há espécimes que possuem 
uma cobertura mais densa, às vezes separadas em grupos de aglomerações por pequenas "valas". Entretanto, a química medular e a morfologia estão em conformidade com os demais. Devido à variedade destas formas e número de intermediários observados, aceitamos estes espécimes como formas extremas quanto à quantidade e aspecto dos isídios.

Parmotrema endosulphureum (Hillmann) Hale é bastante parecida quanto ao formato e hábito geral do talo, porém difere pela medula fortemente amarelada contendo um ácido do grupo girofórico ao invés de ácido lecanórico. Donha (2005) cita esporos bem maiores $(19,0-23,0 \mu \mathrm{m})$ e conídios sublageniformes ao invés de filiformes, bem menores $(5,0-$ $7,0 \mu \mathrm{m})$ que os de $P$. tinctorum. Foi também notado que os espécimes de $P$. tinctorum apresentam lobos mais largos e mais arredondados em média que os de $P$. endosulphureum.

Parmotrema pseudotinctorum (Abbayes) Hale (Krog \& Swinscow 1981; Fleig 1997), foi descrita com isídios inflados. Krog \& Swinscow (1981) comentam ter encontrado uma grande variação no formato dos isídios no material africano, ainda maior que a encontrada por Fleig (1997) no Rio Grande do Sul, sinonimizando $P$. pseudotinctorum com $P$. tinctorum alegando não encontrarem diferenças quanto ao tamanho dos esporos e dos conídios, perfuração de apotécios ou preferência de substratos, mencionando na descrição de $P$. tinctorum que uma divisão específica era, portanto, inapropriada neste caso. Não foram encontrados espécimes com isídios inflados na área de estudo, cuja forma e a química fossem semelhantes às de P. tinctorum.

\section{Referências bibliográficas}

Andrade, M.A.B. 1967. Contribuição ao conhecimento da ecologia das plantas das dunas do litoral do Estado de São Paulo. Boletim da Faculdade de Filosofia, Ciências e Letras da Universidade de São Paulo - Botânica 22: 3-170.

Andrade, M.A.B. \& Lamberti, A. 1965. A Vegetação. In A. Azevedo (coord.) A Baixada Santista - Aspectos Geográficos (Vol. 1): 151-177. Ed da Universidade de São Paulo. São Paulo.

Asahina, Y. \& Shibata, S. 1954. Chemistry of Lichen Substances. Japan Society for the Promotion of Science. Ueno, Tóquio. 240p.

Benatti, M.N. 2005. Os gêneros Canomaculina, Parmotrema e Rimelia (Parmeliaceae, Ascomycetes) no litoral centro-sul do estado de São Paulo. Dissertação de Mestrado. Instituto de Botânica, São Paulo.

Benatti, M.N. \& Marcelli, M.P. 2007. Gêneros de fungos liquenizados dos manguezais do Sul-Sudeste do Brasil, com enfoque no manguezal do Rio Itanhaém, Estado de São Paulo. Acta Botanica Brasilica 21(4): 863-878.

Brako, L., Dibben, M.J. \& Amaral, I. 1985. Preliminary Notes on the macrolichens of Serra do Cachimbo, Northcentral Brazil. Acta Amazonica, suplemento 15(1-2): 123-135.

Brodo, I.M.; Sharnoff, S.D. \& Sharnoff, S. 2001. Lichens of North America. New Haven \& London, Yale University Press. 795 p.

Bungartz, F. 2001. Analysis of lichen substances. Em http://ces.asu.edu/ ASULichens/plb 400/laboratory chemistry/tlc.html. Acessado em outubro de 2004

Canêz, L.S. 2005. A Família Parmeliaceae na localidade de Fazenda da Estrela, Município de Vacaria, Rio Grande do Sul, Brasil. Dissertação de Mestrado. Instituto de Botânica, São Paulo.

CETESB, 1985. Baixada Santista-Memorial Descritivo: Carta do Meio Ambiente e de sua Dinâmica. São Paulo. 33 p.

Culberson, W.L., Egan, R.S. \& Esslinger, T.L. 2005. Recent literature on lichens. Internet: http://www.nhm.uio.no/botanisk/bot-mus/lav/sok_rll. htm. [Presented on the Web by E. Timdal. First posted 1997.04.14, latest update 2005.03.29]

Donha, C.G. 2005. Os gêneros Canomaculina, Parmotrema e Rimelia (Ascomycota Liquenizados) na Área de Proteção Ambiental de Guaraqueçaba, Paraná, Brasil. Dissertação de Mestrado. Universidade Federal do Paraná.

Eiten, G. 1970. A Vegetação do Estado de São Paulo. Boletim do Instituto de Botânica 7: 1-22.

Eliasaro, S. 2001. Estudio taxonomico y floristico sobre las Parmeliaceae sensu stricto (Ascomycota liquenizados) del Segundo Planalto del Estado de Paraná, Brasil. Tese de Doutorado. Facultad de Ciencias Exactas y Naturales, Universidad de Buenos Aires. Buenos Aires

Eliasaro, S. \& Donha, C.G. 2003. The genera Canomaculina and Parmotrema (Parmeliaceae, lichenized Ascomycota) in Curitiba, Paraná State, Brazil. Revista Brasileira de Botânica 26(2): 239-247.

Elix, J.A. 1994. Parmotrema. In Flora of Australia, Lichens. Introduction, Lecanorales 2. 55: 140-162. Australia Government Publishing Service, Canberra.

Feuerer, T.E. (ed.) 2005. Checklists of lichens and lichenicolous fungi. Versão I Junho de 2006. In http://www.checklists.de.

Fink, B. 1905. How to collect and study lichens. The Bryologist 8(2): 22-27.

Fleig, M. 1995. Lichens from "Casa de Pedra" and surroundings, Bagé, Rio Grande do Sul, Brazil. In: Daniëls, F. J. A., Schulz, M. \& Peine, J. (eds.): Flechten Follmann. Contributions to lichenology in Honour of Gerhard Follmann. Geobotanical and Phytotaxonomical Study Group, Botanical Institute, University of Cologne, Cologne, pp. 415-426.

Fleig, M. 1997. Os gêneros Parmotrema, Rimelia e Rimeliella (LichenesAscomycota, Parmeliaceae) no Rio Grande do Sul, Brasil. Tese de Doutorado, Instituto de Biociências da Universidade de São Paulo.

Fleig, M., \& Riquelme, I. 1991. Liquens de Piraputanga, Mato Grosso do Sul, Brasil. Acta Botanica Brasilica 5(1): 3-12.

Galloway, D.J. 1985. Flora of New Zealand - lichens. Wellington, Government Printer. 662 p.

Hale, M.E. 1960. A revision of the South American species of Parmelia determined by Lynge. Contributions from the United States National Herbarium 36(1): 1-41.

Hale, M.E. 1965. A Monograph of the Parmelia subgenus Amphigymnia. Contributions from the United States National Herbarium 36(5): 193-358.

Hale M.E. 1974. Notes on species of Parmotrema (Lichenes: Parmeliaceae) containing yellow pigments. Mycotaxon 1: 105-116.

Hale, M.E. 1977. New species in the lichen genus Parmotrema Massalongo. Mycotaxon 5(2): 432-448.

Hale, M.E. 1979. How to know the Lichens. The Pictured-Key Nature Series. Dubuque, Iowa: WM. C. Brown Company Publishers. Dubuque. 246 p.

Huneck, S. \& Yoshimura, I. 1996. Identification of Lichen Substances Springer-Verlag, Berlin, Heidelberg. 493 p.

Krog, H. \& Swinscow, T.D.V. 1981. Parmelia subgenus Amphigymnia (lichens) in East Africa. Bulletin of British Museum of Natural History (Bot.) 9(3): 143-231.

Kurokawa, S. 1993. Nepalese genera and species of the Parmeliaceae with notes on three additional and one rare species. Annals of the Tsukuba Botanical Garden 12: 75-81.

Kurokawa, S. \& Lai, M-jou 2001: Parmelioid lichen genera and species in Taiwan. Mycotaxon 77: 225-284.

Kurokawa, S. \& Moon, K-H. 1998. Three new species and a new combination in Parmotrema (Parmeliaceae). Bulletin of the Botanical Garden of Toyama 3: 17-23.

Lamberti, A. 1969. Contribuição ao Conhecimento da Ecologia das Plantas do Manguezal de Itanhaém. Boletim da Faculdade de Filosofia, Ciências e Letras da Universidade de São Paulo - Botânica 23: 1 - 217.

Louwhoff, S.H.J.J. \& Elix, J.A. 1999. Parmotrema and allied lichen genera in Papua New Guinea. Bibliotheca Lichenologica 73: 1-152.

Lynge, B. 1914. Die Flechten der ersten Regnellschen Expedition. Die Gattungen Pseudoparmelia gen. nov. und Parmelia Ach. Arkiv för Botanik 13(13): 1-172.

Marcelli, M.P. 1990 (1991). Aspects of the foliose lichen flora of the southern-central coast of São Paulo State, Brazil. In D.J. Galloway 
(Ed). Tropical Lichens: Their Systematics, Conservation, and Ecology, Systematics Association Special Volume 43, p. 151-170. Clarendon Press, Oxford.

Marcelli MP. 2004. Checklist of lichens and lichenicolous fungi of Brazil. Version 1: June 2004. http://www.biologie.uni-hamburg.de/checklists/ brazil $1 . h t m$.

Marcelli, M. P., Jungbluth, P., Benatti, M. N, Spielmann, A. A., Canêz, L. S., Cunha, I. P. R. \& Martins, M. F. N. 2007. Some new species and combinations of Brazilian lichenized fungi. Bibliotheca Lichenologica 96: $209-227$

Nash III, T.H. \& Elix, J.A. 2002. Parmotrema. In: Nash III, T.H., Ryan, B.D., Gries, C. \& Bungartz, F. (eds.). Lichen Flora of the greater Sonoran Desert Region. Volume 1. Lichens Unlimited, Arizona State University, Tempe, Arizona, USA. p. 318-329.

Orange, A., James, P.W. \& White, F.J. 2001. Microchemical methods for the identification of lichens. The British Lichen Society. 101p.

Osorio, H.S. 1972. Contribution to the lichen flora of Uruguai VII. A preliminary catalogue. Comunicaciones Botánicas del Museo de Historia Natural de Montevideo. 4(56): 1-46.

Osorio, H.S. 1977. Contribution to the lichen flora of Brazil II. Lichens from Guarapuava, Paraná State. Dusenia 10(2): 101-102.

Osorio, H.S., Aguiar, L.W. \& Zanette, V.C. 1980. Contributions to the lichen flora of Brazil VII. Lichens from Montenegro and Triunfo, Rio Grande do Sul State. Comunicaciones Botánicas del Museo de Historia Natural de Montevideo 4(62): 1-8.
Ribeiro, C.H. 1998. A família Parmeliaceae (Ascomycota liquenizados) em Regiões montanhosas dos estados de Minas Gerais, Rio de Janeiro e São Paulo. Dissertação de Mestrado, Instituto de Biociências da Universidade de São Paulo.

Santos, E.O. 1965. Características climáticas. In A. Azevedo (coord.) A Baixada Santista - Aspectos Geográficos (Vol. 1): 95-150. Ed. da Universidade de São Paulo. São Paulo.

Sipman, H.J.M. 2004. Mason Hale's key to Parmotrema, revised edition: key to wide-lobed parmelioid species occurring in Tropical America (genera Canomaculina, Parmotrema, Rimelia, Rimeliella). http://www. bgbm.org/sipman/keys/neoparmo.htm. Acessado em julho de 2005.

Spielmann, A.A. 2005. A família Parmeliaceae (fungos liquenizados) nos barrancos e peraus da encosta da Serra Geral, no Vale do Rio Pardo, Rio Grande do Sul, Brasil. Dissertação de Mestrado. Instituto de Botânica, São Paulo.

Swinscow, T.D.V. \& Krog, H. 1988. Macrolichens of East Africa. London, British Museum of Natural History. 390 p.

Walker, J.W. \& James, P.W. 1980. A revised guide to microchemical techniques for the identification of lichen products. Bulletin of the British Lichen Society 46 (supl.): 13-29.

White, F.J. \& James, P.W. 1985. A new guide to microchemical techniques for the identification of lichen substances. Bulletin of the British Lichen Society 57 (supl.): 1-41.

Winnem, B. 1975. Parmelia subgenus Amphigymnia in Ethiopia. Norwegian Journal of Botany 22: 139-166. 